\title{
Improved Quality of Liquefied Petroleum Gas via Non-Stirred Blending
}

\author{
Z. Zakaria \\ Department of Petroleum Engineering \\ Faculty of Chemical and Energy Engineering, Uiversiti Teknologi Malaysia \\ 81310 Johor Bahru Johor Malaysia \\ N. Ibrahim \\ Department of Petroleum Engineering \\ Faculty of Chemical and Energy Engineering, Uiversiti Teknologi Malaysia \\ 81310 Johor Bahru Johor Malaysia \\ M.S.Amin \\ Department of Petroleum Engineering \\ Faculty of Chemical and Energy Engineering, Uiversiti Teknologi Malaysia \\ 81310 Johor Bahru Johor Malaysia \\ A. Samsuri \\ Department of Petroleum Engineering \\ Faculty of Chemical and Energy Engineering, Uiversiti Teknologi Malaysia \\ 81310 Johor Bahru Johor Malaysia \\ I.Ismail \\ Department of Petroleum Engineering \\ Faculty of Chemical and Energy Engineering, Uiversiti Teknologi Malaysia \\ 81310 Johor Bahru Johor Malaysia
}

\begin{abstract}
Liquefied Petroleum Gas (LPG) which contains more than 0.1\% mole of butadiene is classified as a carcinogen and mutagen and regulatory have set the limit of butadiene to be below $0.5 \%$ mole in LPG mixture. LPG suppliers in Malaysia are facing problem since butadiene level from one port exceeded $0.5 \%$ mole. By blending of LPG from other ports might produce LPG products which satisfy the regulatory limit. The study focused on homogeneous blending time in a $17.28 \mathrm{~m}^{3}$ tank without artificial mechanical equipment through simulation modelling by Fluent 6.2.16 with two sources of LPG which were Ports A and B. The results showed that as the volume of LPG with butadiene increased, the butadiene level in mixed LPG also increased. The mass fraction between Ports A and B was below than $93 \%$ and $7 \%$ produced mixed LPG product within the regulatory limit. The blending time is approximately 3.98 hours to achieve homogeneous product mixture with a constant flow rate of $0.52 \mathrm{~kg} / \mathrm{s}$. Numerical modelling reveals that the effect of liquid-liquid diffusion by Wilke-Chang correlation does not significantly affect the blending time for homogeneous mixture. In fact the required blending time is shorter compared to blending time estimated by numerical modeling.
\end{abstract}

Keywords: LPG; butadiene; non-stirred blending; numerical modeling; simulation modelling;

\section{INTRODUCTION}

Liquefied Petroleum Gas (LPG) is stored and shipped as liquids which easily liquefied under pressure at ambient temperature. LPG contains two main components which are propane and butane with butadiene as the minor component. Butadiene is a hazardous chemical which may cause cancer and genetic defects by inhalation [1]. LPG for commercial use which contains more than $0.1 \%$ of any substance that classified as carcinogenic is required to be classified as carcinogenic $[1,2]$. Even though butadiene is a minor component, it shall limit the composition below $0.5 \%$ mole due to regulatory requirement [3]. Other reason for limiting the butadiene content in LPG is butadiene has an explosion limit of 2.0-11.5\% volume wider compared to propane and butane which are $2.1-9.5 \%$ volume and $1.8-8.4 \%$ volume, respectively [4]. It means that the more butadiene present in LPG can cause the explosion limit becomes wider.

Composition of propane and butane plays an important role which reflects the properties of LPG [5, 6]. There are two sources of LPG in Peninsular Malaysia; one imported from abroad through Port A and the other source from refinery plant at Port B. There is a problem in LPG composition at Port A where the level of butadiene exceeds the regulatory limit of 
$0.5 \%$ mole and is considered as off-specification product. The supplier comes out with an idea to blend the LPG from Port A with LPG at Port B. LPG from Port B contains less butadiene level which is $0.01 \%$ mole lower than Port A which is $0.51 \%$ mole. Mixing is one of the common unit operations employed in chemical industries. It is used for blending of liquids, homogenization of mixtures, heat transfer operation, mass transfer operation and prevention of deposition of solid particles. Impellers are the conventional devices used for mixing purpose in industries [7]. But they are very expensive for large storage tanks and underground tanks [8]. Diffusion, one of mixing process method, is the transport of mass that occurs due to a gradient in chemical potential of a component in the system which occurs in all phases of substances. Equivalently, the gradient in concentration can also be used as a driving force in the diffusion process. In gases and liquids, diffusion coefficients are typically around $10^{-5} \mathrm{~m}^{2} / \mathrm{s}$ and $10^{-9} \mathrm{~m}^{2} / \mathrm{s}$, respectively [9]. Molecular diffusion or molecular transport can be defined as the transfer or movement each individual molecule by random through a fluid. The molecules diffusion is assumed travel in straight line only and chance their directions whenever collide with other molecules [10].

In many processes, diffusion occurs simultaneously with other phenomena, such as chemical reactions [11]. When diffusion is the slowest phenomena, it limits the overall rate of the process. Accurate models for mass transport are therefore a prerequisite for the design of many industrial processes and the interpretation of diffusion experiments [7]. Distinguish self-diffusion and mutual diffusion is important in diffusion of fluids. Self diffusion describes the motion of individual molecules whereas mutual diffusion can be related to collective motion of one component and is responsible for mass transport. Therefore, mutual diffusion is the relevant phenomena in practice. Diffusion coefficients are a function of concentration, temperature and pressure and not depend on the magnitude of the concentration or chemical potential gradient [12]. The concentration dependence of diffusivities in liquids is often overlooked in chemical engineering applications. To investigate the concentration dependence of diffusion coefficients, the required experimental effort is large [13]. As experiments on multi component diffusion are difficult and time consuming, a detailed understanding of the concentration dependence of diffusion is currently lacking, especially for multi component systems [14]. Computational Fluid Dynamic (CFD) simulations are a useful method in this respect as one can directly study the effect of molecular interactions on diffusion coefficients [14]. There are two theories commonly used for the description of diffusion which are generalized Fick's law and Maxwell-Stefan [9].

The blending between two different specifications of LPG can reduce the level of butadiene content in LPG whenever the mixture achieves homogeneous blending. Variable quantity of these two different LPG compositions is used to study the homogeneous blending time. Therefore the objectives of the study were to estimate the optimum mass fraction mixing, homogeneous blending time and analyze factors that affect the homogeneous blending time.

\section{METHODOLOGY}

\section{A. Blending Process}

To analyze the homogeneous blending time due to butadiene diffusivity in off-spec LPG from Port A through in-spec LPG from Port B, analytical, numerical and simulation modelling have been developed as highlighted in Figure 1.

LPG contains butadiene of more than $0.5 \%$ moles is considered an off-spec product. Two different compositions of butadiene off-spec and in-spec are given in Table 1. Table 2 shows the operating conditions of LPG for blending process.

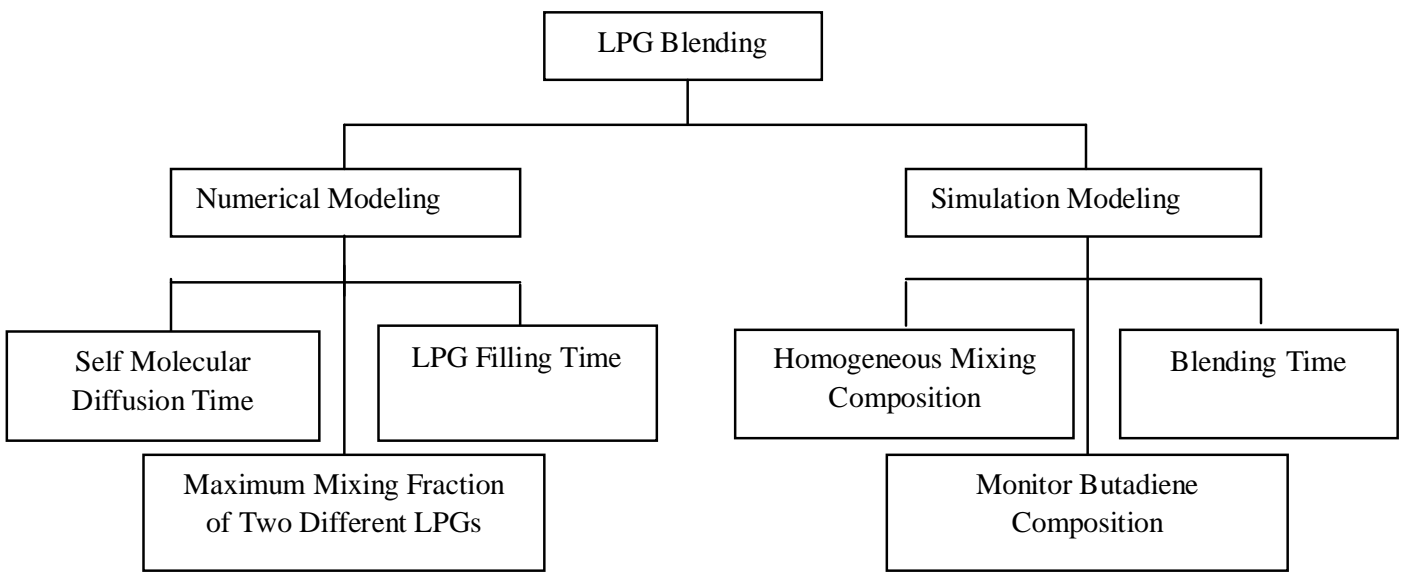

Figure 1. Numerical and Simulation Modeling of LPG Blending

Off-spec LPG from Port A contains butadiene of more than $0.5 \%$ mole would be blended with in-spec LPG contains lower butadiene in a mixer tank by natural mixing. The mixer tanks specifications for the blending process are shown by Table 3.

Table 1. Compositions of LPG from different Ports 


\begin{tabular}{lcc}
\hline Hydrocarbon & $\begin{array}{c}\text { Port A (off-spec) } \\
\text { \% Mole }\end{array}$ & $\begin{array}{c}\text { Port B (in-spec) } \\
\% \text { Mole }\end{array}$ \\
\hline Components & 24.23 & 49.09 \\
Propane & 75.23 & 50.9 \\
Butane & 0.51 & 0.01 \\
Heavien hydrocarbon & Negligible & Negligible \\
\hline
\end{tabular}

Table 2. Operating conditions of LPG from Different Ports

\begin{tabular}{lll}
\hline Operating Conditions & Port A (off-spec) & Port B (in-spec) \\
\hline Pressure, bar & 5 & 5 \\
Temperature, ${ }^{\circ} \mathrm{C}$ & 25 & 25 \\
Density, $\mathrm{kg} / \mathrm{MT} / \mathrm{hr}$ & 0.573 & 0.546 \\
Flow Rate, $\mathrm{Mr}$ & 1.872 & - \\
\hline
\end{tabular}

Table 3. Blending Tank Specification

\begin{tabular}{lc}
\hline Specification & Measurement \\
\hline Length, m & 5.983 \\
Internal Diameter, m & 1.829 \\
Volume of LPG 85\% (MT) & 8.0196 \\
Wall thickness, mm & 30 \\
Inlet pipe size, inch & 2 \\
\hline
\end{tabular}

Initially, LPG from Port B is pumped into the mixer tank with variable volumes which followed by LPG from Port A until a maximum permitted volume ( $85 \%$ of tanks total volume or 8.0196 tonnes). The blending time is calculated for every different fraction between the two sources of LPG. Diffusion molecules of butadiene are considered occur from high to low concentrations which should be achieved below $0.5 \%$ mole of butadiene as shown in Figure 2. Variable quantities of friction mixing between off-spec and in-spec LPG were carried out to analyze the effect of different ratio of mixing volumes to blending time for homogeneous mixture as shown in Table 4.

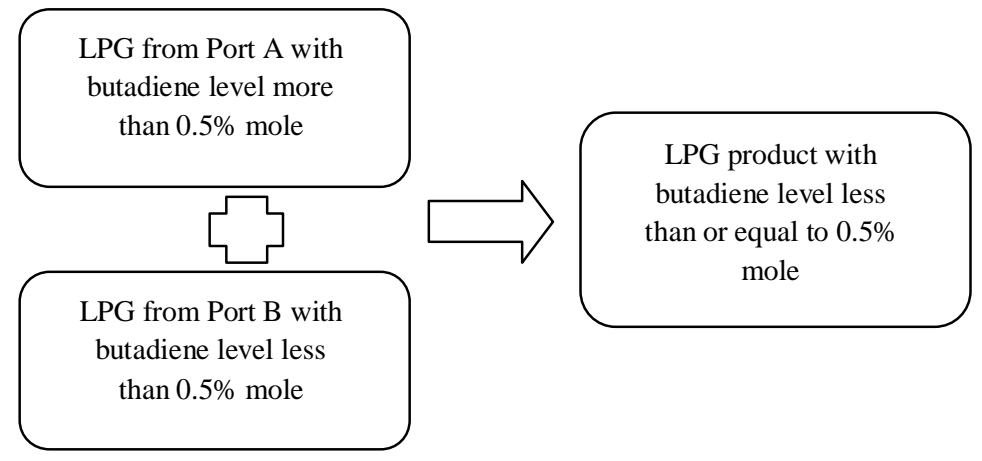

Figure 2. Blending of Two Different LPG Composition

\section{B. Numerical Modeling}

The numerical and simulation modeling were carried out to find the best blending fraction which required different blending time and mole fraction of butadiene after the blending process was monitored and maintained at $\leq 0.5 \%$ mole. In order to estimate the blending time for both LPGs to achieve a homogeneous mixture, numerical modeling was carried out which diffusion and external force such as pumping flow rate were taken into consideration. To solve numerical modelling, LPG from Port A was considered as solute A while LPG from Port B was considered as solvent B. The flow process for blending time estimation by numerical modelling is shown in Figure 3.

Table 4. Different blending fractions of LPG

\begin{tabular}{llc}
\hline No. of Mixing & Mass percentage \% of 8.0196 tonnes of total $L P G$ \\
\cline { 2 - 3 } & Port A & Port B \\
\hline 1 & 10 & 90 \\
2 & 20 & 80 \\
\hline
\end{tabular}




\begin{tabular}{|c|c|c|c|c|c|}
\hline 3 & & 30 & & 70 & \\
\hline 4 & & 40 & & 60 & \\
\hline 5 & & 50 & & 50 & \\
\hline 6 & & 60 & & 40 & \\
\hline 7 & & 70 & & 30 & \\
\hline 8 & & 80 & & 20 & \\
\hline \multirow[t]{4}{*}{9} & & 90 & & 10 & \\
\hline & $\begin{array}{c}\text { Calculate molecular } \\
\text { weight of LPG from } \\
\text { Port B }\end{array}$ & & $\begin{array}{l}\text { Calculate viscosity } \\
\text { mixture of LPG } \\
\text { from Port B }\end{array}$ & & $\begin{array}{l}\text { Calculate molar } \\
\text { volume of LPG } \\
\text { from Port B }\end{array}$ \\
\hline & $\begin{array}{l}\text { Calculate self } \\
\text { molecular diffusion } \\
\text { time }\end{array}$ & & $\begin{array}{c}\text { Estimate the } \\
\text { diffusivity } \\
\text { coefficient of LPG }\end{array}$ & & $\begin{array}{l}\text { Select operating } \\
\text { temperature of LPG }\end{array}$ \\
\hline & $\begin{array}{l}\text { Calculate self } \\
\text { molecular flux of } \\
\text { LPG from Port A }\end{array}$ & & $\begin{array}{l}\text { Calculate the flux } \\
\text { based on flow rate } \\
\text { of LPG from Port A }\end{array}$ & & $\begin{array}{l}\text { Calculate the total } \\
\text { flux to estimate the } \\
\text { actual blending time }\end{array}$ \\
\hline
\end{tabular}

Figure 3. Flow Process of Numerical Modelling

Wilke-Chang correlation is applied to estimate the diffusivity coefficient of LPG as shown in Equation (1) [10]:

$$
\mathrm{D}_{\mathrm{AB}}=1.173 \times 10^{-16}\left(\phi \mathrm{M}_{\mathrm{B}}\right)^{1 / 2} \frac{\mathrm{T}}{\mu_{\mathrm{B}} \mathrm{V}_{\mathrm{A}}^{0.6}}
$$

where $M_{B}$ is the molecular weight of solvent $B, \mu_{B}$ is the viscosity of $B, V_{A}$ is the solute molar volume at the boiling point which can be obtained from Table 4, T is operating temperature in Kelvin (K) and $\varnothing$ is an "association parameter" of the solvent which considered as 1.0 [8].

LPG from Port A with high percentage of butadiene is considered diffuse into LPG with low percentage of butadiene, and the solute molar volume, $\mathrm{V}_{\mathrm{A}}$ is calculated using Equation (2).

$$
\mathrm{V}_{\mathrm{A}}=\mathrm{nC}+\mathrm{nH}
$$

where $\mathrm{n}$ is the total number of atom for carbon and hydrogen in hydrocarbon chemical formula, $\mathrm{C}$ is atomic number for carbon atom and $\mathrm{H}$ is atomic number for hydrogen atom.

Equation (3) is applied to predict the viscosity of mixture solution of LPG from Port B which contains the main two hydrocarbons which are propane and butane. Butadiene has very low composition which can be negligible to mixture's viscosity. The dynamic viscosity of hydrocarbon listed in Table 5 can be used to estimate the viscosity of the mixture.

$$
\operatorname{In} \mu=x_{1} \operatorname{In} \mu_{1}+x_{2} \operatorname{In} \mu_{2}
$$

where $\mu$ is the viscosity of the solution, and $x_{1}, x_{2}, \mu_{1}$, and $\mu_{2}$ are the mole fractions and viscosities of the two components in a binary mixtures, respectively. 
Table 5. Dynamic Viscosity (centipose) of Hydrocarbon

\begin{tabular}{llllll}
\hline Components & $\begin{array}{l}\text { Empirical } \\
\text { Formula }\end{array}$ & \multicolumn{4}{c}{$\begin{array}{c}\text { Dynamic viscosity at } \\
\text { different Temperature }{ }^{\circ} \mathrm{C}\end{array}$} \\
\cline { 3 - 6 } & & 10 & 20 & 25 & 30 \\
\hline Propane & C3H8 & 0.125 & & 0.1192 & \\
Butane & C4H10 & 0.19 & 0.174 & 0.1665 & 0.159 \\
Butadiene & C4H6 & & & & 0.1395 \\
& & & & & \\
\hline
\end{tabular}

To estimate the blending time of two different LPG compositions, Equation (4) is applied where is $D_{A B}$ is diffusivity coefficient of solute A through solvent B which has been calculated by Equation (1). LPG from Port A which contains $\%$ mole of butadiene more than $0.5 \%$ is considered as solute A and LPG from Port B which contains $\%$ mole of butadiene less than $0.5 \%$ is considered solvent $\mathrm{B}$.

$$
\mathrm{t}_{\mathrm{F}}=\frac{\rho_{\mathrm{A}} \mathrm{A}\left(\mathrm{Z}_{\mathrm{F}}^{2}-\mathrm{Z}_{\mathrm{o}}^{2}\right) \mathrm{R} \mathrm{TP} \mathrm{BM}_{\mathrm{BM}}}{2 \mathrm{M}_{\mathrm{A}} \mathrm{D}_{\mathrm{AB}} \mathrm{P}\left(\mathrm{P}_{\mathrm{A} 1}-\mathrm{P}_{\mathrm{A} 2}\right)}
$$

where $t_{F}$ is diffusion time, $\rho_{A}$ is density of LPG from Port A and $z_{F}$ is solute travelling distance. The solute travelling distance is considered as molecule of LPG from Port A flowing from inlet area until the longest distance inside the mixer tank as shown in Figure 4.

Since molecules of LPG from Port A have reached the end of tanks wall surface which is the longest travelling distance and the mole \% of butadiene closes to $0.5 \%$ for the entire of inside tank, the liquid LPG mixture could be considered as a homogeneous mixture. The diffusion time at that particular time which butadiene mole $\%$ achieves $0.5 \%$ is considered as blending time for homogeneous liquid mixture. $\mathrm{R}$ is gas constant $8314 \mathrm{~Pa} / \mathrm{kg} . \mathrm{mole} . \mathrm{K}$, $\mathrm{T}$ is operating temperature in Kelvin $(\mathrm{K}), \mathrm{p}_{\mathrm{BM}}$ is ratio of partial pressure, $\mathrm{M}_{\mathrm{A}}$ is molecular weight of solute, $\mathrm{D}_{\mathrm{AB}}$ is diffusivity coefficient of solute $\mathrm{A}$ through solvent $\mathrm{B}, \mathrm{P}$ is operating pressure, $\mathrm{P}_{\mathrm{A}}$ is partial pressure of solute $\mathrm{A}$. A the cross sectional area of liquid in the mixer tank.

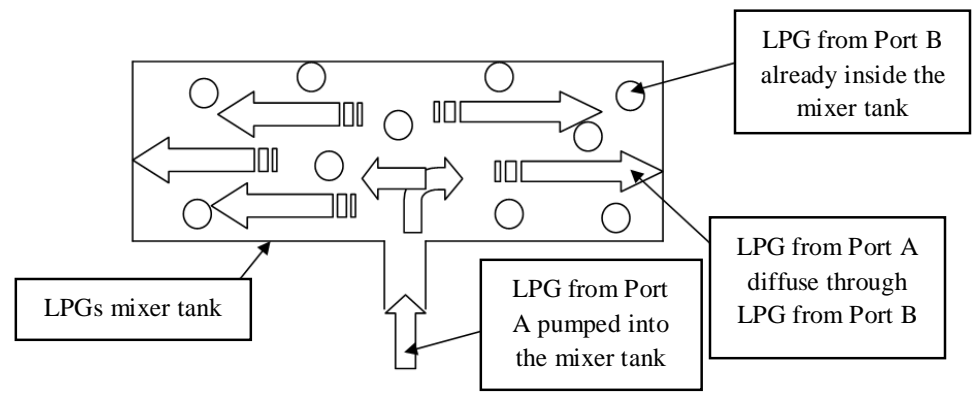

Figure 4. LPG from Port A Travelling Distance

$$
\mathrm{N}_{\mathrm{A}}=\frac{\mathrm{D}_{\mathrm{AB}}{ }^{\mathrm{P}}}{\mathrm{RT}\left(\mathrm{Z}_{2}-\mathrm{Z}_{1}\right) \mathrm{P}_{\mathrm{BM}}}\left(\mathrm{P}_{\mathrm{A} 1}-\mathrm{P}_{\mathrm{A} 2}\right)
$$

Calculated diffusion time, $\mathrm{t}_{\mathrm{F}}$ is considered as self molecular diffusion which would be corrected by flux from inlet LPG from Port A. Flux for inlet LPG can be solved by Equation(5).

The self molecular flux which can be calculated using Equation (5) would be scaled to flux of inlet LPG flow rate to generate the actual blending time which respect to each mixing fraction of the two-source LPGs as listed in Table 4. 
$C$.

\section{Simulation Modeling}

Gambit 2.2.30 software is used as modelling meshing tool for the mixing boundary model. This pre-processor software is able to generate the model and create meshed model simulation works. Modeling steps for fluid mixing in the tank by the Gambit software are executed as per Figure 5. After modelling of LPG mixing tank has completed, the meshed model file can be opened in Fluent 6.2.16 software to start simulation process as shown in Figure 6.

Simulation by Fluent is run based on time step size and numbers of iteration. For this simulation, number of time steps is set to 1 second for every 10 numbers of iteration. For the initial simulation, species mass fraction in boundary condition setting is set to LPG from Port B data as shown in Table 6.

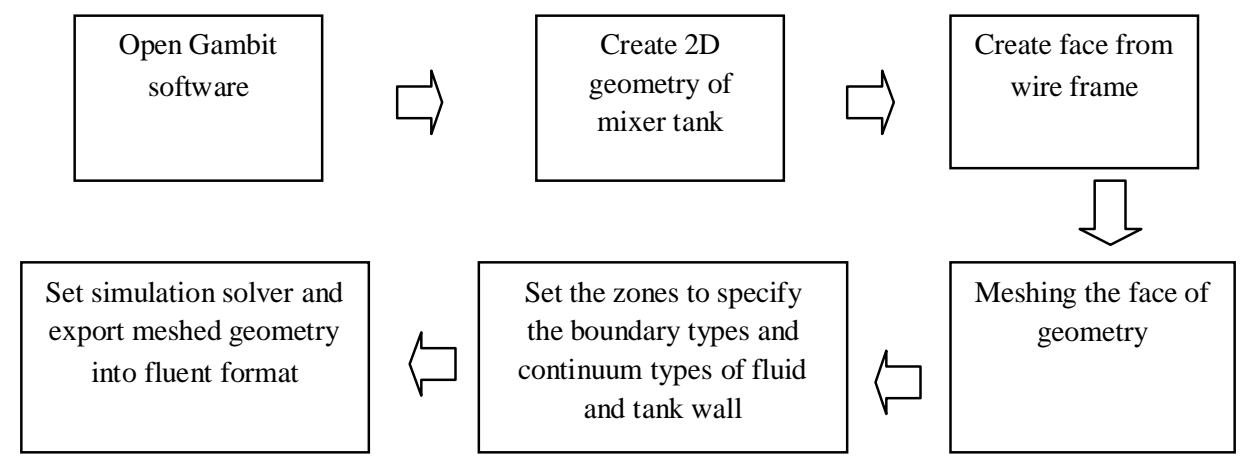

Figure 5. Flow Process to Create Meshed Geometry by Gambit Software

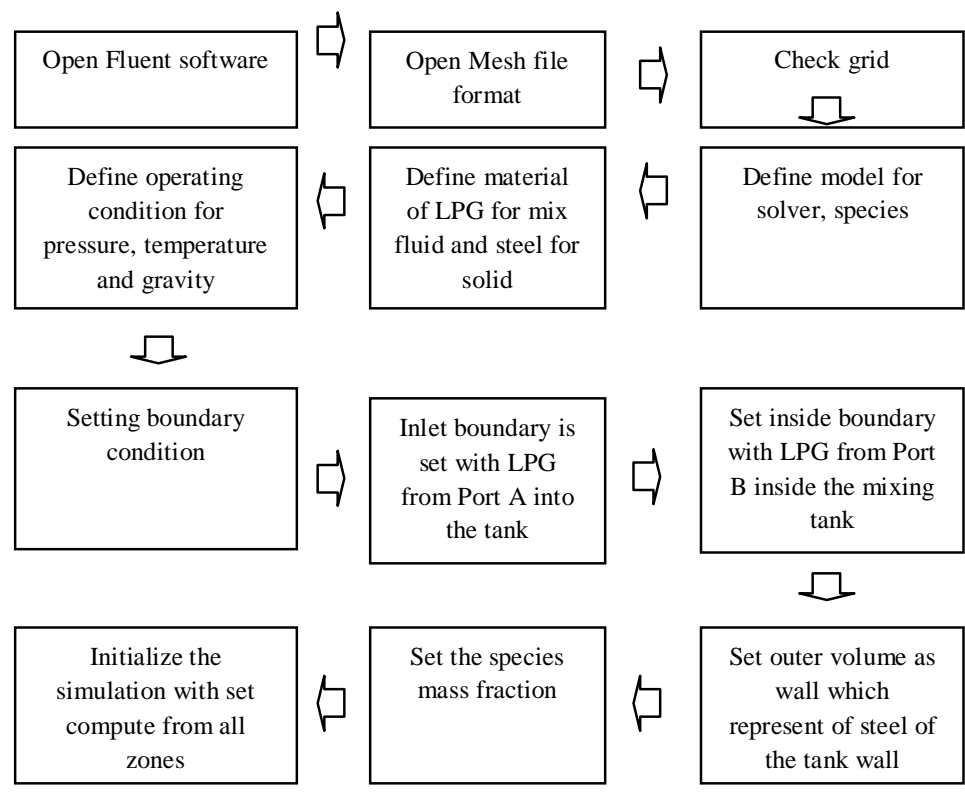

Figure 6. Flow Process of Simulation by Fluent Software

After the simulation has carried out by Fluent, the mass fraction setting at boundary condition is updated to mass fraction of LPG from Port A with the appropriate time step as calculated by numerical method. Simulation data is observed and analyzed for every determined time step.

Table 6. Circulation Time of LPG Filling

\begin{tabular}{lllll}
\hline & $\begin{array}{l}\text { Mass Fraction } \\
\text { LPG from } \\
\text { Port B }\end{array}$ & $\begin{array}{l}\text { Circulation } \\
\text { Time }(s) \text { for } \\
\text { filling LPG from } \\
\text { Port B }\end{array}$ & $\begin{array}{l}\text { Mass Fraction } \\
\text { LPG from }\end{array}$ & $\begin{array}{l}\text { Circulation Time }(s) \\
\text { for filling LPG from } \\
\text { Port A }\end{array}$ \\
\hline $\begin{array}{l}\text { Mixing 1 } \\
\text { Composition }\end{array}$ & $10 \%$ & 13880 & $90 \%$ & 1542 \\
\hline
\end{tabular}




\begin{tabular}{|c|c|c|}
\hline Propane & 0.4226 & 0.1954 \\
\hline Butane & 0.5773 & 0.7993 \\
\hline Butadiene & 0.0001 & 0.0053 \\
\hline
\end{tabular}

In order to determine the optimum blending fraction, mass and mole fractions are calculated for different blending fractions between LPG from Port A, LPG from Port B and LPG products after blending has taken placed in the mixer tank. The mass and mole fraction data is important to monitor the mixing fraction used between LPG from Port A and Port B which does not produce LPG with butadiene level exceeds $0.5 \%$ mole. This data is also used as input for simulation setting of mass fraction for respective LPG compositions from Ports A and B. Table 7 shows the different mixing fractions between LPG Ports A and $\mathrm{B}$ during blending at $0.52 \mathrm{~kg} / \mathrm{s}$.

Table 7. Mass and Mole Fraction for LPG from Port A, Port B and Products after Blending with Constant Pumping Rate of $0.52 \mathrm{~kg} / \mathrm{s}$

\begin{tabular}{|c|c|c|c|c|}
\hline \multirow[t]{2}{*}{ No. of Mixing } & \multicolumn{4}{|c|}{ Mass Percentage \% of 8.0196 tonne of Total Liquefied Petroleum Gas (LPG) } \\
\hline & \multicolumn{2}{|c|}{ Port A } & \multicolumn{2}{|c|}{ Port B } \\
\hline 1 & \multicolumn{2}{|c|}{10} & \multicolumn{2}{|c|}{90} \\
\hline \multicolumn{5}{|c|}{ LPG Composition After Blending } \\
\hline LPG Components & Weight Fraction & Mole Fraction & $\begin{array}{c}\text { LPG Port A Filling } \\
\text { Time }\end{array}$ & $\begin{array}{l}\text { LPG Port B Filling } \\
\text { Time }\end{array}$ \\
\hline Propane & 0.3999 & 0.4675 & 1542 & 13880 \\
\hline Butane & 0.5995 & 0.5319 & & \\
\hline Butadiene & 0.0006 & 0.0006 & & \\
\hline No. of Mixing & \multicolumn{2}{|c|}{ Port A } & \multicolumn{2}{|c|}{ Port B } \\
\hline 2 & \multicolumn{2}{|c|}{20} & \multicolumn{2}{|c|}{80} \\
\hline \multicolumn{5}{|c|}{ LPG Composition After Blending } \\
\hline LPG Components & Weight Fraction & Mole Fraction & $\begin{array}{c}\text { LPG Port A Filling } \\
\text { Time }\end{array}$ & $\begin{array}{l}\text { LPG Port B Filling } \\
\text { Time }\end{array}$ \\
\hline Propane & 0.3772 & 0.4437 & 3084 & 12337 \\
\hline Butane & 0.6217 & 0.5552 & & \\
\hline Butadiene & 0.0012 & 0.0011 & & \\
\hline No. of Mixing & \multicolumn{2}{|c|}{ Port A } & \multicolumn{2}{|c|}{ Port B } \\
\hline 3 & \multicolumn{2}{|c|}{30} & \multicolumn{2}{|c|}{70} \\
\hline \multicolumn{5}{|c|}{ LPG Composition After Blending } \\
\hline LPG Components & Weight Fraction & Mole Fraction & $\begin{array}{c}\text { LPG Port A Filling } \\
\text { Time (s) }\end{array}$ & $\begin{array}{c}\text { LPG Port B Filling } \\
\text { Time (s) }\end{array}$ \\
\hline Propane & 0.3544 & 0.4197 & 4626 & 10795 \\
\hline Butane & 0.6439 & 0.5787 & & \\
\hline Butadiene & 0.0017 & 0.0016 & & \\
\hline No. of Mixing & \multicolumn{2}{|c|}{ Port A } & \multicolumn{2}{|c|}{ Port B } \\
\hline 4 & \multicolumn{2}{|c|}{40} & \multicolumn{2}{|c|}{60} \\
\hline \multicolumn{5}{|c|}{ LPG Composition After Blending } \\
\hline LPG Components & Weight Fraction & Mole Fraction & $\begin{array}{l}\text { LPG Port A Filling } \\
\text { Time (s) }\end{array}$ & $\begin{array}{l}\text { LPG Port B Filling } \\
\text { Time (s) }\end{array}$ \\
\hline Propane & 0.3317 & 0.3953 & 6168 & 9253 \\
\hline Butane & 0.6661 & 0.6025 & & \\
\hline Butadiene & 0.0022 & 0.0021 & & \\
\hline No. of Mixing & \multicolumn{2}{|c|}{ Port A } & \multicolumn{2}{|c|}{ Port B } \\
\hline 5 & \multicolumn{2}{|c|}{50} & \multicolumn{2}{|c|}{50} \\
\hline \multicolumn{5}{|c|}{ LPG Composition After Blending } \\
\hline LPG Components & Weight Fraction & Mole Fraction & $\begin{array}{l}\text { LPG Port A Filling } \\
\text { Time (s) }\end{array}$ & $\begin{array}{l}\text { LPG Port B Filling } \\
\text { Time (s) }\end{array}$ \\
\hline Propane & 0.309 & 0.3707 & 7711 & 7711 \\
\hline Butane & 0.6883 & 0.6267 & & \\
\hline Butadiene & 0.0027 & 0.0027 & & \\
\hline No. of Mixing & & & & \\
\hline 6 & & & & \\
\hline & & osition After B & & \\
\hline
\end{tabular}




\begin{tabular}{|c|c|c|c|c|}
\hline LPG Components & Weight Fraction & Mole Fraction & $\begin{array}{c}\text { LPG Port A Filling } \\
\text { Time (s) }\end{array}$ & $\begin{array}{c}\text { LPG Port B Filling } \\
\text { Time (s) }\end{array}$ \\
\hline Propane & 0.2863 & 0.3457 & 9253 & 6168 \\
\hline Butane & 0.7105 & 0.6511 & & \\
\hline Butadiene & 0.0032 & 0.0032 & & \\
\hline No. of Mixing & \multicolumn{2}{|c|}{ Port A } & \multicolumn{2}{|c|}{ Port B } \\
\hline 7 & \multicolumn{2}{|c|}{70} & \multicolumn{2}{|c|}{30} \\
\hline \multicolumn{5}{|c|}{ LPG Composition After Blending } \\
\hline LPG Components & Weight Fraction & Mole Fraction & $\begin{array}{l}\text { LPG Port A Filling } \\
\text { Time (s) }\end{array}$ & $\begin{array}{c}\text { LPG Port B Filling } \\
\text { Time (s) }\end{array}$ \\
\hline Propane & 0.2636 & 0.3203 & 10795 & 4626 \\
\hline Butane & 0.7327 & 0.6759 & & \\
\hline Butadiene & 0.0038 & 0.0037 & & \\
\hline No. of Mixing & \multicolumn{2}{|c|}{ Port A } & \multicolumn{2}{|c|}{ Port B } \\
\hline 8 & \multicolumn{2}{|c|}{80} & \multicolumn{2}{|c|}{20} \\
\hline \multicolumn{5}{|c|}{ LPG Composition After Blending } \\
\hline LPG Components & Weight Fraction & Mole Fraction & $\begin{array}{l}\text { LPG Port A Filling } \\
\text { Time (s) }\end{array}$ & $\begin{array}{c}\text { LPG Port B Filling } \\
\text { Time (s) }\end{array}$ \\
\hline Propane & 0.2408 & 0.2947 & 12337 & 3084 \\
\hline Butane & 0.7549 & 0.7010 & & \\
\hline Butadiene & 0.0043 & 0.0043 & & \\
\hline No. of Mixing & \multicolumn{2}{|c|}{ Port A } & \multicolumn{2}{|c|}{ Port B } \\
\hline 9 & \multicolumn{2}{|c|}{90} & \multicolumn{2}{|c|}{10} \\
\hline LPG Components & Weight Fraction & Mole Fraction & $\begin{array}{l}\text { LPG Port A Filling } \\
\text { Time (s) }\end{array}$ & $\begin{array}{l}\text { LPG Port B Filling } \\
\text { Time (s) }\end{array}$ \\
\hline Propane & 0.2181 & 0.2687 & 13880 & 1542 \\
\hline Butane & 0.7771 & 0.7265 & & \\
\hline Butadiene & 0.0048 & 0.0048 & & \\
\hline
\end{tabular}

Based on the table, every blending of LPG produced different LPG product composition. At the last mixing fraction of number 9, 90\% weight fraction of LPG Port A mixed with 10\% weight fraction of LPG Port B have successfully produce $0.48 \%$ butadiene in the mixture of LPG products. To further analyze the optimum weight fraction of LPG mixing, the mixing fraction of LPG has been detailed out from 90 mole $\%$ until 95 mole $\%$ of LPG Port A as shown in Figure 7.

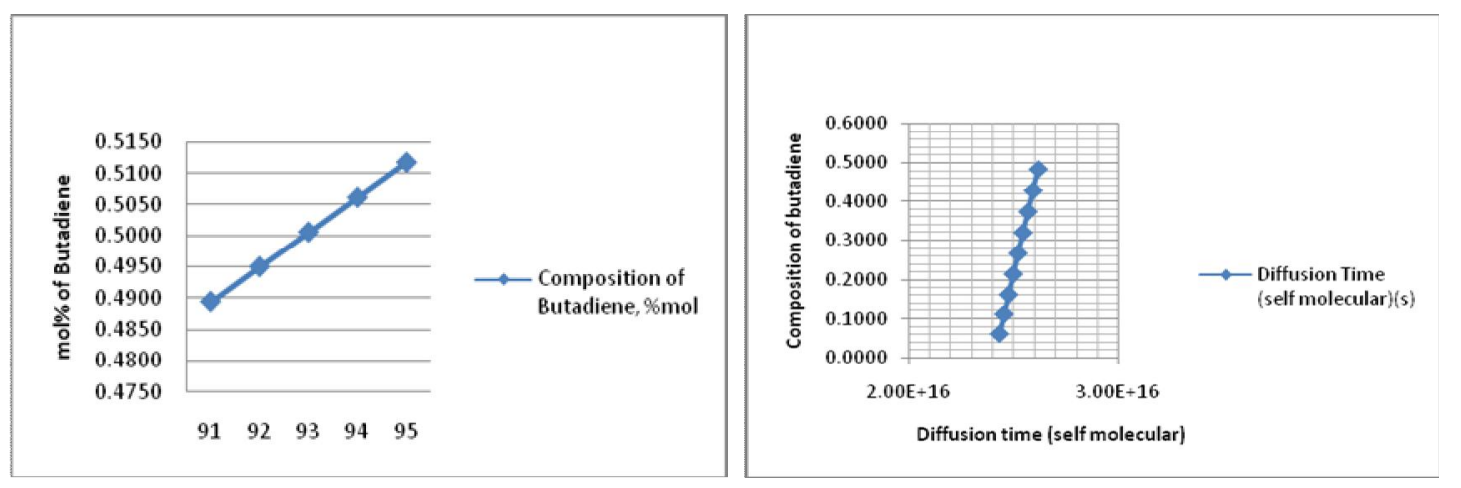

Figure 7. Composition of Butadiene versus Blending Fraction of LPG Port A

Figure 8. Composition of Butadiene versus Diffusion Time

Based on the Figure 7, it is shown that percent mole of butadiene in the LPG mixture after blending process would exceed the regulatory limit of $0.5 \%$ mole if the mixing fraction of LPG Port A was increased to more than $93 \%$ of total LPG product. This fact proved that $93 \%$ of LPG Port A and 7\% of LPG Port B of total LPG blending are considered as an maximum mixing fraction to produce 8.0196 tonnes of LPG product with butadiene level at $0.5 \%$ mole.

Figure 8 shows the diffusion time taken by butadiene molecules in the LPG mixture which respect to its composition. This fact proved that the increase of butadiene composition in the solute mixture which is LPG Port A would increase its diffusion time in the LPG mixture. Butadiene would take longer time to diffuse through solvent mixture which is LPG Port B since the concentration of butadiene in the solute increased. The calculated diffusion time shows butadiene in LPG Port A took very long time to diffuse through LPG Port B which proved that the homogeneous blending time of LPG is 
not significantly affected by molecular diffusion. In other word, the blending time to achieve homogeneous mixture for LPG is depending on distribution rate rather than diffusion rate during the mixing process.

Based on molecular diffusion of Fick's Law, the homogeneous blending time will be faster when the molecular travelling path decreases. This molecular mass transport will increase when the volume of solvent decreases. This concept indicate that molecular diffusion of solute will increase when the resistance in solvent decreases. This shows that the homogeneous blending time will be longer when the volume of LPG from Port B increases in the mixing tank compared to inlet volume of LPG from Port A. In order to observe the effect of distribution rate on blending time, the maximum mixing by weight fraction of 93\% LPG Port A and 7\% LPG Port B was chosen for further simulation which is more productivity in terms of quantity of LPG productions.

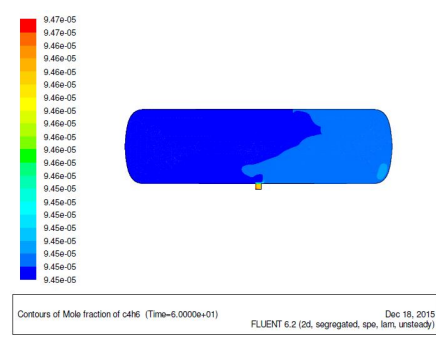

a) Mole Fraction at 1 second

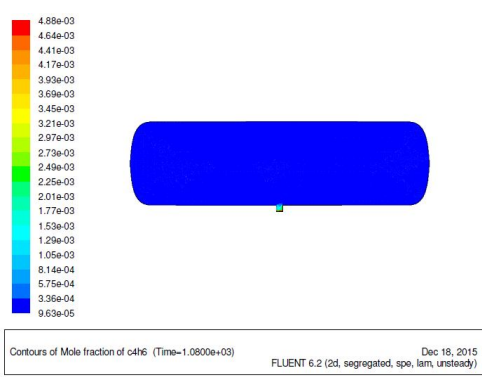

c) Mole Fraction at1080 seconds

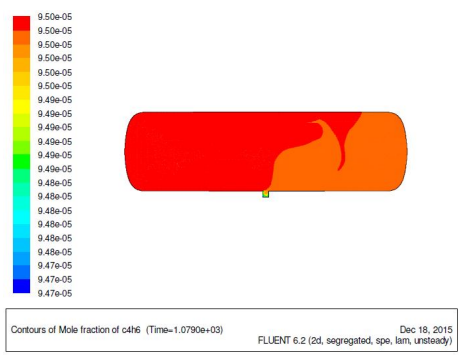

b) Mole Fraction at 1079 seconds

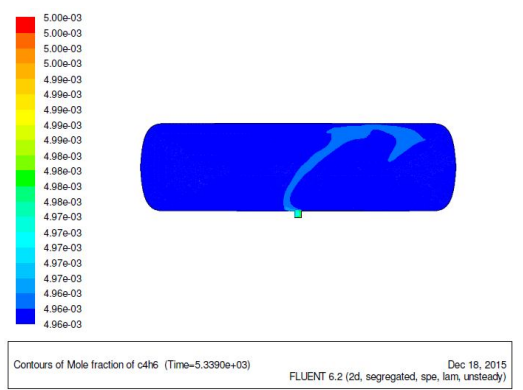

d) Mole Fraction at 5339 seconds

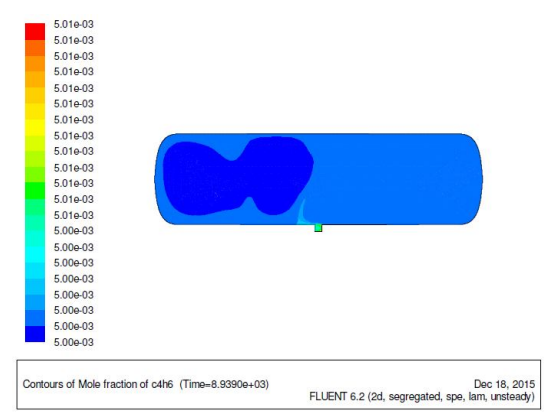

e) Mole Fraction at 8939 seconds

Figure 9. Butadiene Profiles at different Distribution Times

Figure 9 shows the distribution profile of butadiene. Figure 9(a) shows that LPG Port B was started to flowing into the mixer tank. From the simulation results, distribution of butadiene has just started at the bottom of mixer tank inlet which is represented by low fraction (blue colour) at the entire of inside tank. Figure 9(b) shows that LPG Port B is occupying the mixer tank which is represented by red colour. During this time the mass fraction of inlet LPG Port B has been updated to mass fraction of LPG Port A. Figure 9(c) shows that LPG Port A has started to mix with LPG Port B in the mixer tank which is represented by sudden rise of butadiene mole fraction at the bottom inlet of the tank. Figure 9(d) shows that mole fraction of butadiene closes to 0.5 by mixing of LPG Port A with LPG Port B after 1.48 hours. Figure 9(e) shows that the mole fractions of butadiene are homogeneous which is represented by 0.5 of blue colour which fills the entire mixer tank. This simulation results reveal that the optimum mixing fraction of 8.0196 tonne LPG products which consist of $73 \%$ of LPG Port A and 7\% of LPG Port B would take 2.48 hours to be blended homogeneously. Based on the numerical modeling, with constant pumping rate of $0.52 \mathrm{~kg} / \mathrm{s}$, the LPG Port A filling into the mixer tank can be expected to complete in 14342 seconds (3.98 hours) but the simulation results proved that the homogeneous mixture could be achieved in 1.5 hours faster than liquid pumping rate with butadiene mole fraction is set at $0.5 \%$. This phenomenon is caused by other factor that influences the 
homogeneous blending time of LPG which is the circulation effect during filling process. This would result in the accumulation of butadiene in the tank and is also affected by the unsteady state condition of blending process.

\section{CONCLUSION}

The blending time to achieve homogeneous mixture for quality LPG is depending on distribution rate rather than diffusion rate. LPG blending would achieve homogeneous state and butadiene level would reach 0.5 mole \% before the LPG filling was completed and the mixing time was proportional to the circulation time due to volume of liquid in the tank and flow rate entrained by the tank inlet. Numerical modelling reveals that the effect of liquid-liquid diffusion by Wilke-Chang correlation did not significantly affect the blending time for homogeneous mixture where the required blending time was shorter compared to blending time estimated by numerical modelling.

\section{REFERENCES}

[1] Dennis, A. S. (2002). Plant Engineer's Reference Book. Butterworth-Heinemann, Reed Educational and Professional Publishing Ltd., Oxford.

[2] Hughes, K., Meek, M.E., Walker M., and Beauchamp R. (2001). 1,3-Butadiene: Human Health Aspects, Concise International Chemical Assessment Document 30, World Health Organization Geneva.

[3] NGC Energy Sdn. Bhd. (2013). NGC Energy Liquefied Petroleum Gas. Safety Data Sheet. SDS No. OG/SDS/MY/LPG.

[4] American Chemistry Council. (2010). Butadiene Product Stewardship Guidance Manual.

[5] Zainal, Z and Azeman, M. (2013). The Effect of Filling Weight to LPG Residue in Storage. International Journal of Engineering, Business and Enterprise Application.

[6] Vinayagamoorthy and Sankar. (2012). Service Quality Of Domestic Lpg: An Empirical Study. International Journal Of Business And General Management (Ijbgm) Vol.1, Issue 1 11-26 Iaset. Tamil Nadu, India: Associate Professor, Department Of Commerce, Periyar University, Salem-11. Tamil Nadu, India 2 Ph.D. Research Scholar, Department Of Commerce, Periyar University, Salem-11.

[7] Lane, A. G. C. and Rice, P. (1982). An Experimental Investigation of Jet Mixing Employing An Inclined Side Entry Jet. Transaction of The Institution of Chemical Engineers. 60:171-176.

[8] Kailas L. W. J. and Vijay, S. (2008). CFD Modelling And Simulation Of Jet Mixed Tanks, Engineering Applications of Computational Fluid Mechanics. Vol. 2. No. 2, pp.155-171. Department Of Chemical Engineering, Indian Institute Of Technology (Iit), Roorkee - 247667 India.

[9] Liu, X. (2013). Diffusion in Liquids Equilibrium Molecular Simulations and Predictive Engineering Models, Master of Science in Biochemical Engineering, Delft University of Technology, geboren te Daqing, China.

[10] Christie, J. G. (2003). Transport Processes and Separation Process Principles, Fourth Edition, Pearson Prentice Hall, University of Minnesota.

[11] Gianni, O., Chiara G., Elisabetta, B. and Roberto, M. (2013). Mixing of Two Miscible Liquids in T-Shaped Microdevices, Chemical Engineering Transactions, Vol. 32. The Italian Association of Chemical Engineering.

[12] Coldrey, P. W. (1978). Jet Mixing. Paper to I.Chem. Eng. Course, University of Bradford, England.

[13] Grenville, R. K., Mak A. T. C. and Ruszkowski S. W. (1992). Blending of Fluids In Mixing Vessels By Turbulent Recirculating Jets. The 1992 IchemE Research Event.

[14] Mansur, E. A., Wang Y. D. And Dai Y.Y. (2008). Computational Fluid Dynamic Simulation of Liquid-Liquid Mixing in a Static Double-T-shaped Micromixer, The Chinese Journal of Process Engineering, Vol.8 No.6, The State Key Lab. Chem. Eng., Dept. Chem. Eng., Tsinghua University, Beijing 100084, China. 